NASA Contractor Report 3504

\title{
Ultrasonic and Mechanical \\ Characterizations of Fatigue \\ States of Graphite Epoxy \\ Composite Laminates
}

James H. Williams, Jr., Hursit Yuce, and Samson S. Lee

GRANT NSG-3210

JANUARY 1982 
NASA Contractor Report 3504

\section{Ultrasonic and Mechanical \\ Characterizations of Fatigue \\ States of Graphite Epoxy \\ Composite Laminates}

James H. Williams, Jr., Hursit Yuce, and Samson S. Lee

Massachusetts Institute of Technology

Cambridge, Massacbusetts

Prepared for

Lewis Research Center

under Grant NSG-3210

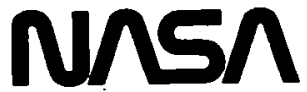

National Aeronautics

and Space Administration

Scientific and Technical

Information Branch 


\section{INTRODUCTION}

Fiber reinforced composites are inherently nonhomogeneous materials in which fabrication procedures can affect their service reliability without effect on their visual appearance. Williams and Dol1 [1] observed in a unidirectional graphite fiber epoxy composite that a small change $\left(14^{\circ} \mathrm{C}\right)$ in the precure temperature resulted in significant changes in transfiber compressive fracture strength and the transfiber compressioncompression fatigue life. Because (for some modes of) fatigue the failure of graphite fiber composites tends to be sudden and occurs without any visible evidence of damage [2], any means of nondestructively monitoring fatigue damage or predicting fatigue behavior of graphite fiber composites is likely to enhance their effective use.

In the investigation conducted by Williams and Doll [1], they observed that the ultrasonic attenuation of the composite in the asfabricated state can be an indicator of the composite fatigue life. The purpose of the present study is to further explore the relationship between ultrasonic attenuation and fatigue survivability of graphite fiber epoxy composites fabricated under various processing temperatures and pressures. 
ULTRASONIC NONDESTRUCTIVE EVALUATION OF COMPOSITES

Significant changes in ultrasonic attenuation have been reported for a small change $\left(14^{\circ} \mathrm{C}\right)$ in the precure temperature of graphite fiber epoxy composites [1,3]. U1trasonic parameters have been correlated directly with strength parameters. Vary et al. [4-6] have proposed an ultrasonic quantity called the "stress wave factor" which can be correlated with the tensile strength and the interlaminar shear strength of graphite fiber composites. Ultrasonic attenuation has been correlated with the shear strength of graphite fiber polyimide composites [7], the residual tensile strength of impact-damaged graphite fiber epoxy composites [8], and the residual tensile strength of flawed fiberglass polyester (sheet molding compound) composites [9].

Except for the already mentioned study by Williams and Doll [1] where the ultrasonic attenuation was related to the fatigue life of composites, very little has been reported on the relationship between ultrasonic parameters and the fatigue state of materials. Truell and Hikata [10] have monitored ultrasonic attenuation changes as a function of fatigue cycles on various aluminum alloys. They observed that an increase in attenuation always occurred prior to cyclic failure. The number of cycles at which this increased attenuation occurred varied from $30 \%$ to approximately $100 \%$ of the fatigue 1 ife. 
The material was Hercules $\Lambda \mathrm{S} / 3501-6$ graphite fiber epoxy composite in the eight-ply $[0, \pm 45,0]_{s}$ laminate configuration. Ten (10) $27 \mathrm{~cm} \mathrm{x}$ $40 \mathrm{~cm}$ laminates were fabricated under various cure temperatures and pressures as summarized in Table 1 . The resulting laminate thicknesses are shown in Table 1 also. Fiber, matrix and void volume fractions were determined by acid digestion tests in accordance with ASTM D3171-73 [11], using at least four (4) samples from various locations of each laminate. Five (5) fatigue specimens were cut from each laminate. A schematic of the specimen is shown in Fig. 1a. (Note that the $0^{\circ}$ fiber direction is along the length of the specimen.) A specimen designation number has been assigned to each laminate as shown in Table 1. Specimen designation number 5 was fabricated exactly in accordance with the Hercules specifications [12]. 
EXPERIMENTAL EQUIPMENT AND PROCEDURES

Fatigue Testing

A Baldwin model SF-2-U Universal Fatigue Machine was used for the flexural fatiguing of the specimens. The fatigue machine was forcecontrolled and was capable of applying up to $\pm 111 \mathrm{~N}$ with a maximum displacement range of $\pm 1.27 \mathrm{~cm}$.

The specimens were subjected to sinusoidal flexural fatigue in the cantilever mode as shown in Fig. 1b. The fatiguing was performed with a force $\mathrm{P}$ varying between $\pm 73.5 \mathrm{~N}$ at $30 \mathrm{~Hz}$ at room temperature. For the identical cantilever geometry, the static fracture load was $110 \mathrm{~N}$ for specimens designated as No. 5 and which were fabricated according to the Hercules specifications [12]. The fatigue tests were terminated when the maximum deflection of $\pm 1.27 \mathrm{~cm}$ was reached.

The flexural stiffness of each specimen was determined by dividing the load $P$ with the resulting end deflection. The flexural stiffness measurements were made both before fatigue and intermittently during fatigue testing. Because the flexural stiffness was proportional to the bending rigidity which varied with the third power of the specimen thickness, the flexural stiffness data for specimens of various thicknesses were normalized with respect to a reference thickness. The reference thickness has been taken as $0.103 \mathrm{~cm}$ which is the thickness of specimens designated as No. 5.

\section{U1trasonic Through-Transmission Attenuation}

Ultrasonic attenuation of longitudinal waves propagating in the thickness direction of the specimens was measured by the ultrasonic through-transmission system shown schematically in Fig. 2. The system consisted of a pulsed oscillator (Arenburg model PG-652C) for generating the sinusoidal waves; a low frequency inductor (Arenburg mode1 LFT-500); broadband transmitting and receiving transducers (Acoustic Emission Technology (AET) FC-500) having an approximately flat sensitivity of $-85 \mathrm{~dB}$ (relative to $1 \mathrm{~V} / \mu \mathrm{Bar}$ ) over the 0.1 to $3.0 \mathrm{MHz}$ frequency range; a transducer-specimen interface couplant (AET SC-6); and an oscilloscope (Tektronix model 455). Two (2) step attenuators were also used. One attenuator, set at $10 \mathrm{~dB}$, reduced the input signal to $100 \mathrm{~V}$ (peak-topeak) into the transmitting transducer, while a second attenuator, set at $20 \mathrm{~dB}$, reduced the $100 \mathrm{~V}$ signal to $10 \mathrm{~V}$ at the oscilloscope only. No filters were used on either the input or the output signals.

The $2.54 \mathrm{~cm}$ diameter FC-500 transducers were clamped on the specimen at midlength between the tabs. A clamping pressure of $0.31 \mathrm{MPa}$ was applied to the transducer-specimen interface. As shown in [3], this 
pressure exceeds the "saturation pressure", which is defined as the minimum interface pressure that results in the maximum output signal amplitude, all other parameters being held constant. Attenuation measurements were made at $4.0 \mathrm{MHz}$ both before fatigue and intermittently during the fatigue testing.

Because the absolute magnitude of the through-transmission attenuation of the material was not known and because the lack of otherwise identical specimens of different thicknesses precluded its determination by the technique used in [3], all attenuation values were evaluated as the deviation from the (as-fabricated) before-fatigue value of specimens designated as No. 5, based on the arguments which follow.

In measuring through-transmission attenuation in thin structures, the analysis by Lee and Williams [13] should be used to account for multiple reflections within the structure. For the present specimen geometry and assuming an attenuation of the order of that measured by Williams and Lampert [8], the result in [13] can be simplified to

$$
\operatorname{Max} . r_{o, s s} \approx v_{i} F_{1} F_{2} e^{-\alpha L}
$$

where

$$
\begin{aligned}
\text { Max. } \mathrm{v}_{0, s s}= & \text { maximum amplitude of the steady state output voltage } \\
& \text { from the receiving transducer. } \\
\mathrm{v}_{i}= & \begin{array}{l}
\text { amplitude of the input voltage to the transmitting } \\
\text { transducer. }
\end{array} \\
\mathrm{F}_{1}(\omega) \mathrm{F}_{2}(\omega)= & \text { product of the transduction ratios corresponding to } \\
& \text { the transformation of an electrical signal into stress } \\
& \text { and vice versa; where } \mathrm{F}_{1}(\omega) \text { and } \mathrm{F}_{2}(\omega) \text { are frequency, } \\
& \omega, \text { dependent. } \\
\alpha= & \text { attenuation constant. } \\
\mathrm{L}= & \text { specimen thickness. }
\end{aligned}
$$

The error in evaluating the absolute attenuation by the approximation in eqn. (1) is expected to be less than 10\% for pre-fatigued specimens designated as No. 5 which were fabricated under Hercules specifications [12]. The percent error decreases with increasing attenuation and increases with decreasing attenuation.

Using eqn. (1), the $4.0 \mathrm{MHz}$ steady-state output voltage amplitude from the receiving transducer for a specimen fabricated according to the Hercules specifications [12] is defined as 


$$
\left[\operatorname{Max} . v_{o, s s}\right]_{1}=v_{i} F_{1} F_{2} e^{-\alpha_{1} L_{1}}
$$

where $\alpha_{1}$ and $L_{1}$ are the attenuation and thickness of the specimen, respectively. Similarly, the $4.0 \mathrm{MHz}$ steady-state output voltage amplitude from the receiving transducer for a different specimen is

$$
\left[\operatorname{Max} . v_{\mathrm{o}, \mathrm{ss}}\right]_{2}=\mathrm{v}_{i} \mathrm{~F}_{1} \mathrm{~F}_{2} \mathrm{e}^{-\alpha_{2} \mathrm{~L}_{2}}
$$

where $\alpha_{2}$ and $L_{2}$ are the attenuation and thickness of the specimen, respectively. Note that the same $F_{1} F_{2}$ is assumed for the different specimens.

Dividing eqn. (2) by eqn. (3) gives

$$
\frac{\left[\operatorname{Max} \cdot v_{o, s s}\right]_{1}}{\left[\operatorname{Max} \cdot v_{o, s s}\right]_{2}}=\frac{v_{i} F_{1} F_{2} e^{-\alpha_{1} L_{1}}}{v_{i} F_{1} F_{2} e^{-\alpha_{2} L_{2}}}=e^{-\left(\alpha_{1} L_{1}-\alpha_{2} L_{2}\right)}
$$

Taking the natural logarithm of eqn. (4) gives

$$
-\left(\alpha_{1} L_{1}-\alpha_{2} L_{2}\right)=\ln \frac{\left[\operatorname{Max} \cdot v_{o, s s}\right]_{1}}{\left[\operatorname{Max} \cdot v_{o, s s}\right]_{2}}
$$

Rearranging eqn. (5) gives

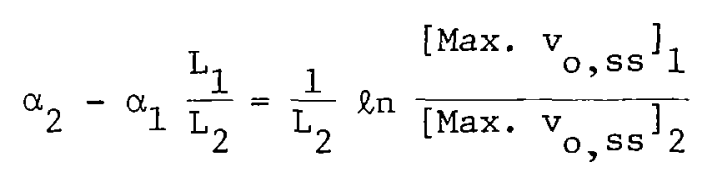

A relative increase in attenuation $\Delta \alpha^{*}$, which is corrected for differences in specimen thickness, can be defined between a specimen of thickness $\mathrm{L}_{2}$ and a specimen of thickness $\mathrm{L}_{1}$ fabricated in accordance with Hercules specifications [12] as

$$
\Delta \alpha^{*}=\alpha_{2}-\alpha_{1} \frac{\mathrm{L}_{1}}{\mathrm{~L}_{2}}
$$

Then eqn. (6) can be rewritten as 


$$
\Delta \alpha^{*}=\frac{1}{L_{2}} \ln \frac{\left[\operatorname{Max} \cdot v_{o, s s}\right]_{1}}{\left[\operatorname{Max} \cdot v_{o, s s}\right]_{2}}
$$

Eqn. (8) gives the relative increase in attenuation $\Delta \alpha^{*}$ in neper/cm when $\mathrm{L}_{2}$ is measured in $\mathrm{cm}$. Note that the specimens designated as No. 5 which were fabricated according to the Hercules specifications [12] have $\Delta \alpha^{*}$ equal to zero before fatigue and a thickness $L_{1}$ of $0.103 \mathrm{~cm}$. 
RESULTS AND DISCUSSIONS

Table 1 is a summary of the mechanical and ultrasonic characterizations of the $[0, \pm 45,0]$ s graphite fiber epoxy composite specimens fabricated in accordance with the indicated cure temperatures and pressures. The entries of the table are discussed in detail under the separate subsections which follow.

Fiber, Matrix and Void Volume Fractions

The fiber and matrix volume fractions for variations in cure temperature and pressure are shown in Fig. 3. In general, an increase in cure temperature produced an increase in fiber volume fraction and a corresponding decrease in matrix volume fraction.

The void volume fraction data are summarized in Table 1. Fig. 4 shows the void volume fraction versus cure temperature. It is observed that, in general, the minimum void volume fraction occurred at a cure temperature of $175^{\circ} \mathrm{C}$. Fig. 5 shows the void volume fraction versus cure pressure. It is observed that for each cure temperature the minimum void volume fraction occurred at a cure pressure of $0.86 \mathrm{MPa}$.

\section{Flexural Stiffness}

The initial flexural stiffness data are summarized in Table 1. Fig. 6 shows the flexural stiffness versus the number of fatigue cycles for specimens fabricated under the various conditions. For each specimen, the flexural stiffness decreased beyond 10,000 fatigue cycles. Fatigue failure is defined arbitrarily as the point when the thickness-normalized stiffness decreases to $12.5 \mathrm{~N} / \mathrm{cm}$. The number of cycles to fatigue failure for each specimen is summarized in Table 1 . With reference to the void volume fraction data in Table 1 , it is observed that, in general, a specimen with a relatively low void volume fraction had a relatively high initial flexural stiffness and a relatively long fatigue life.

\section{Ultrasonic Through-Transmission Attenuation}

The relative initial attenuation data at $4.0 \mathrm{MHz}$ are summarized in Table 1. With reference to the void volume fraction data in Table 1 , the relative initial attenuation versus the void volume fraction of the asfabricated specimens is shown in Fig. 7. The vertical bars through the data points represent the standard deviations of the attenuation measurements. 
It is observed that the relative inftial attenuation increased with the void volume fraction. With reference to the fatigue life data in Table 1 , the relative initial attenuation versus the number of cycles to fatigue failure is shown in Fig. 8. A straight line was fitted by eye to the data.

Fig. 9 shows the relative increase in attenuation $\Delta \alpha^{*}$ versus the number of fatigue cycles for specimens fabricated under the various conditions. For each specimen, the attenuation increased beyond 10,000 fatigue cycles. 
CONCLUSIONS

Eight-ply $[0, \pm 45,0]_{S}$ laminates of Hercules AS/3501-6 graphite fiber epoxy composite have been fabricated using various cure pressures ranging from 0.52 to $0.86 \mathrm{MPa}$ and cure temperatures ranging from 150 to $200^{\circ} \mathrm{C}$. Fiber, matrix and void volume fractions of the as-fabricated laminates have been determined. Specimens were tested in flexural fatigue. U1trasonic through-transmission attenuation at $4.0 \mathrm{MHz}$ and flexural stiffness were determined both before fatigue and intermittently during the fatigue testing.

The mechanical and ultrasonic characterizations of the specimens are summarized in Table 1. The following conclusions can be drawn from this study:

(1) In general, over the temperature range of 150 to $200^{\circ} \mathrm{C}$, the minimum void volume fraction ocurred in specimens cured at $175^{\circ} \mathrm{C}$. The exception is the specimens cured at $0.86 \mathrm{MPa}$ and $200^{\circ} \mathrm{C}$.

(2) Over the pressure range of 0.52 to $0.86 \mathrm{MPa}$, the minimum void volume fraction ocurred in specimens cured at $0.86 \mathrm{MPa}$. Thus, future studies should investigate even higher cure pressures to minimize void content.

(3) In general, an increase in cure temperature produced an increase in fiber volume fraction and a decrease in matrix volume fraction.

(4) Beyond 10,000 cycles, the flexural stiffness decreased with the number of fatigue cycles.

(5) The ultrasonic through-thickness attenuation at $4.0 \mathrm{MHz}$ was correlated with the void volume fraction. Specimens with relatively low void volume fraction had relatively low attenuation.

(6) Beyond 10,000 cycles, the ultrasonic through-transmission attenuation at $4.0 \mathrm{MHz}$ increased with the number of fatigue cycles. Future studies should attempt to use geometrically smaller ultrasonic transducers to enhance the sensitivity by concentrating the ultrasonic wave on the more highly stressed region of the specimens.

(7) The ultrasonic through-transmission attenuation at $4.0 \mathrm{MHz}$ of the as-fabricated laminate has been correlated with the number of fatigue cycles to failure. 
Thus, for the range of fabrication temperatures and pressures considered, significant effects on the mechanical properties of the composite result. This study further indicates the potential usefulness of ultrasonic nondestructive evaluation techniques in the quality assurance of the composite laminates. Finally, in agreement with [1], the ultrasonic attenuation of the as-fabricated composite may be potentially used as an indicator of fatigue life of the composite. 


\section{REFERENCES}

1. J.H. Williams, Jr., and B. Doll, "U1trasonic Attenuation as an Indicator of Fatigue Life of Graphite Fiber Epoxy Composite", Materials Evaluation, Vol. 38, No. 5, May 1980, pp. 33-37.

2. J. Awerbuch and H.T. Hahn, "Fatigue and Proof-Testing of Unidirectional Graphite Epoxy Composites", Fatigue of Filamentary Composite Materials, ASTM STP 636, Ed. by K.L. Reifsnider and K.N. Lauraitis, American Society for Testing and Materials, Philadelphia, PA, 1977, pp. 248-266.

3. J.H. Williams, Jr., H. Nayeb-Hashemi, and S.S. Lee, "U1trasonic Attenuation and Velocity in AS/3501-6 Graphite Fiber Composite", Journal of Nondestructive Evaluation, Vo1. 1, No. 2, 1980, pp. 137-148.

4. A. Vary and K.J. Bowles, "Ultrasonic Evaluation of the Strength of Unidirectional Graphite Polyimide Composites", Proceedings of the Eleventh Symposium on Nondestructive Testing, ASNT and SWI, San Antonio, Texas, 1977, PP. 242-258. (A1so, see NASA TM 73646, Lewis Research Center, April 1977.)

5. A. Vary and K.J. Bowles, "Use of Ultrasonic Acoustic Techniques for Nondestructive Evaluation of Fiber Composite Strength", Proceedings of 33rd Annual Conference, SPI, New York, 1978, Section 24-A, pp. 1-5. (Also, see NASA TM 73813, Lewis Research Center, February 1978.)

6. A. Vary and R.F. Lark, "Correlation of Fiber Composite Tensile Strength with Ultrasonic Stress Wave Factor", J. of Testing and Evaluation, Vol. 7, No. 4, ASTM, April 1979, pp. 185-191. (Also, see, NASA TM 78846, Lewis Research Center, Apri1 1978.)

7. D.T. Hayford, E.G. Henneke, II, and W.W. Stinchcomb, "The Correlation of Ultrasonic Attenuation and Shear Strength in Graphite Polyimide Composites", Journal of Composite Materials, Vol. 11, October 1977, pp. 429-444.

8. J.H. Williams, Jr., and N.R. Lampert, "U1trasonic Evaluation of ImpactDamaged Graphite Fiber Composite", Materials Evaluation, Vol. 38, No. 12, December 1980, pp. 68-72.

9. J.H. Williams, Jr., S.S. Lee, and T.K. Wang, "Quantitative Nondestructive Evaluation of Automotive Glass Fiber Composites", (Under Review).

10. R. Truell and A. Hikata, "Fatigue and Ultrasonic Attenuation", Symposium on Nondestructive Testing, ASTM STP 213, American Society for Testing Materials, Philadelphia, PA, 1957, pp. 63-69. 
REFERENCES (CONT'D)

11. "Standard Method of Test for Fiber Content of Fiber Reinforced Resin Composites", ASTM Part 36, D3171-73, American Society for Testing Materials, Philadelphia, PA, 1976.

12. Graphite Materials, Hercules Inc., Systems Group, Bacchus Works, Magna, Utah, April 1976.

13. S.S. Lee and J.H. Williams, Jr., "Stress Wave Attenuation in Thin Structures by Ultrasonic Through-Transmission", (To appear in the Journal of Nondestructive Evaluation). 
TABLE 1 Summary of Effects of Cure Pressure and Temperature on Void Volume Fraction, Mechanical Properties and Ultrasonic Attenuation on AS/3501-6 Laminates.

\begin{tabular}{|c|c|c|c|}
\hline \multirow{2}{*}{$\begin{array}{c}\text { Cure } \\
\text { Pressure } \\
\text { (MPa) }\end{array}$} & \multicolumn{3}{|c|}{ Cure Temperature $\left({ }^{\circ} \mathrm{C}\right)$} \\
\hline & 150 & 175 & 200 \\
\hline 0.52 & $\begin{aligned} \text { Specimen Designa- } & \text { tion } \#_{1} 1 \\
\mathrm{~V}_{\mathrm{v}} & =2.70 \% \\
\Delta \alpha^{*}= & 0.45 \text { neper } / \mathrm{cm} \\
\mathrm{k}= & 19.60 \mathrm{~N} / \mathrm{cm} \\
\mathrm{N} & =990,000 \\
\mathrm{t} & =0.108 \mathrm{~cm}\end{aligned}$ & $\begin{aligned} \# 2 \\
\mathrm{~V}_{\mathrm{v}}=0.82 \% \\
\Delta \alpha^{*}=-2.20 \text { neper } / \mathrm{cm} \\
\mathrm{k}=26.40 \mathrm{~N} / \mathrm{cm} \\
\mathrm{N}=1,100,000 \\
\mathrm{t}=0.110 \mathrm{~cm}\end{aligned}$ & $\begin{aligned} & \# 3 \\
\mathrm{~V}_{\mathrm{v}}= & 5.09 \% \\
\Delta \alpha^{*}= & 3.50 \text { neper } / \mathrm{cm} \\
\mathrm{k}= & 21.60 \mathrm{~N} / \mathrm{cm} \\
\mathrm{N}= & 226,000 \\
\mathrm{t}= & 0.142 \mathrm{~cm}\end{aligned}$ \\
\hline 0.69 & $\begin{aligned} & \# 4 \\
\mathrm{v}_{\mathrm{v}} & =2.89 \% \\
\Delta \alpha^{\frac{*}{*}}= & -0.60 \text { neper } / \mathrm{cm} \\
\mathrm{k} & =23.70 \mathrm{~N} / \mathrm{cm} \\
\mathrm{N} & =662,000 \\
\mathrm{t} & =0.102 \mathrm{~cm}\end{aligned}$ & $\begin{aligned} & \# 5 \\
v_{\mathrm{v}} & =1.39 \% \\
\Delta \alpha^{*} & =0.00 \\
\mathrm{k} & =26.50 \mathrm{~N} / \mathrm{cm} \\
\mathrm{N} & =2,400,000 \\
t & =0.103 \mathrm{~cm}\end{aligned}$ & $\begin{aligned} & \# 6 \\
\mathrm{v}_{\mathrm{v}} & =5.55 \% \\
\Delta \alpha^{*}= & 11.47 \text { neper } / \mathrm{cm} \\
\mathrm{k} & =22.60 \mathrm{~N} / \mathrm{cm} \\
\mathrm{N} & =128,000 \\
\mathrm{t} & =0.140 \mathrm{~cm}\end{aligned}$ \\
\hline 0.86 & $\begin{aligned} & \# 7 \\
\mathrm{~V}_{\mathrm{v}} & =2.19 \% \\
\Delta \alpha^{*} & =0.70 \text { neper } / \mathrm{cm} \\
\mathrm{k} & =21.10 \mathrm{~N} / \mathrm{cm} \\
\mathrm{N} & =562,000 \\
\mathrm{t} & =0.099 \mathrm{~cm}\end{aligned}$ & $\begin{aligned} \# 8 \\
\mathrm{v}_{\mathrm{v}}=0.19 \% \\
\Delta \alpha^{*}=-5.60 \text { neper } / \mathrm{cm} \\
\mathrm{k}=27.00 \mathrm{~N} / \mathrm{cm} \\
\mathrm{N}=3,552,000 \\
t=0.102 \mathrm{~cm}\end{aligned}$ & $\begin{aligned} & \# 9 \\
\mathrm{~V}_{\mathrm{v}} & =0.10 \% \\
\Delta \alpha^{*} & =-5.52 \mathrm{neper} / \mathrm{cm} \\
\mathrm{k} & =25.70 \mathrm{~N} / \mathrm{cm} \\
\mathrm{N} & =3,162,000 \\
\mathrm{t} & =0.112 \mathrm{~cm}\end{aligned}$ \\
\hline
\end{tabular}

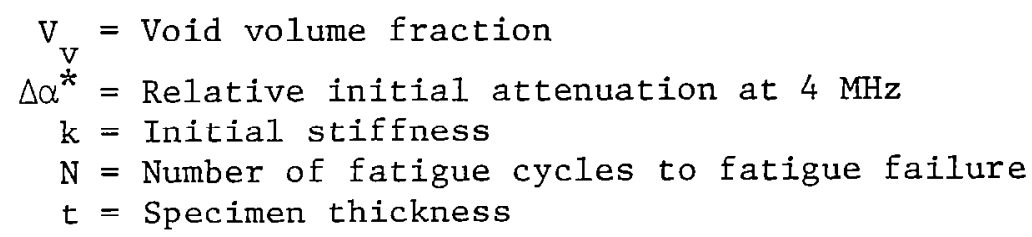



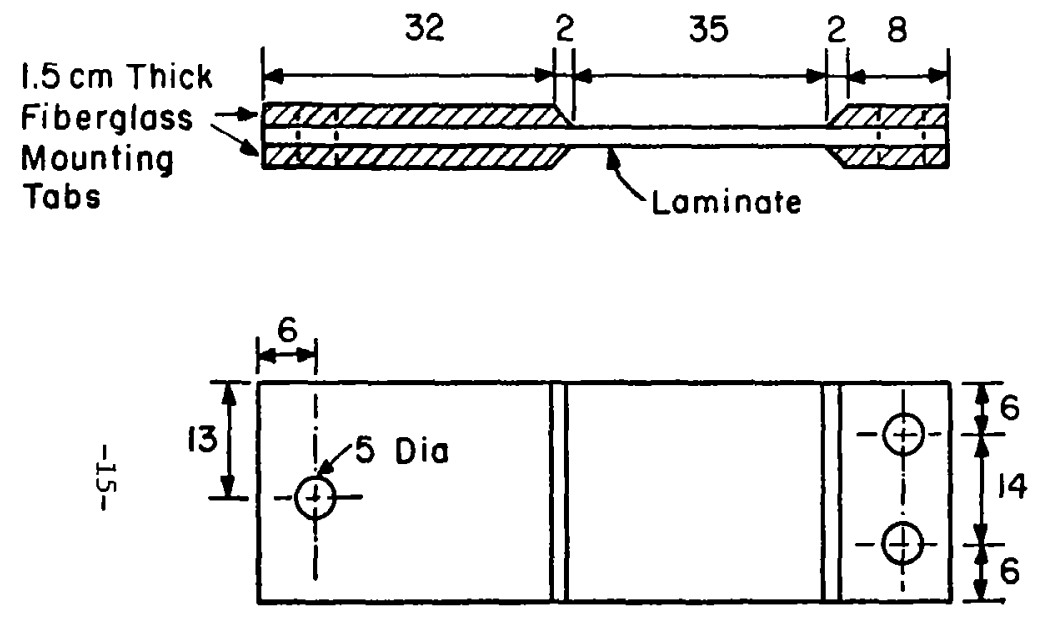

(a)

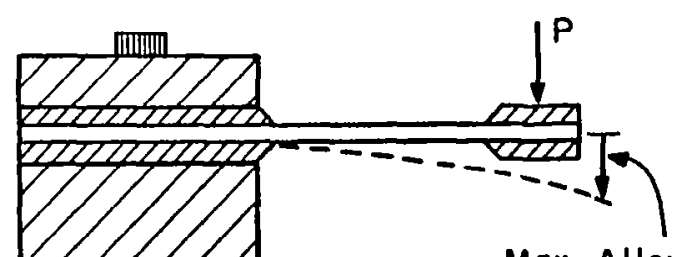

Max. Allowable

Displacement $=12.7$

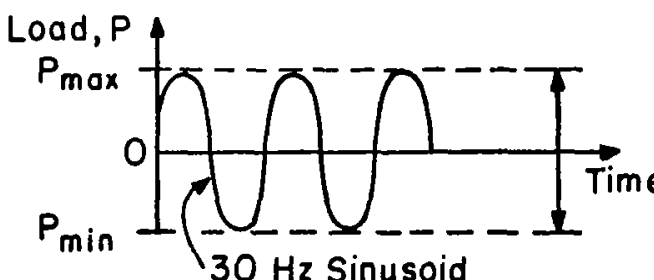

$\Delta P=P_{\text {max }}-P_{\text {min }}$

$R=\frac{P_{\text {min }}}{P_{\text {max }}}=-1$

$\Delta P=147 \mathrm{~N}, P= \pm 73.5 \mathrm{~N}$

(b) Fig. 1 Specimen (a) geometry and (b) loading for fatigue, stiffness, and attenuation characterization.
(Linear dimensions are given in mm.) 
Pulsed Oscillator

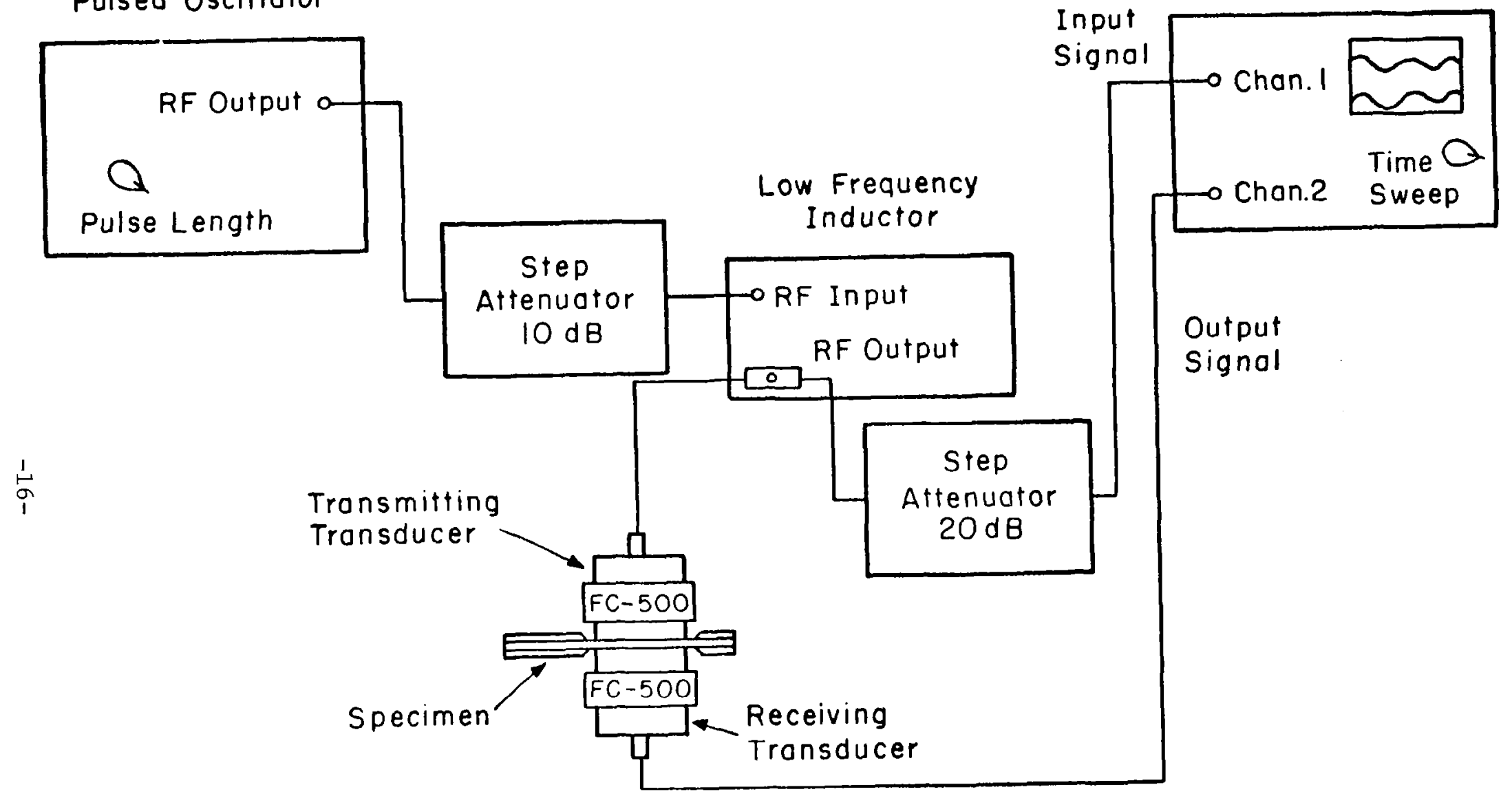

Fig. 2 Systen for ultrasonic through-transmission attenuation measurements. 


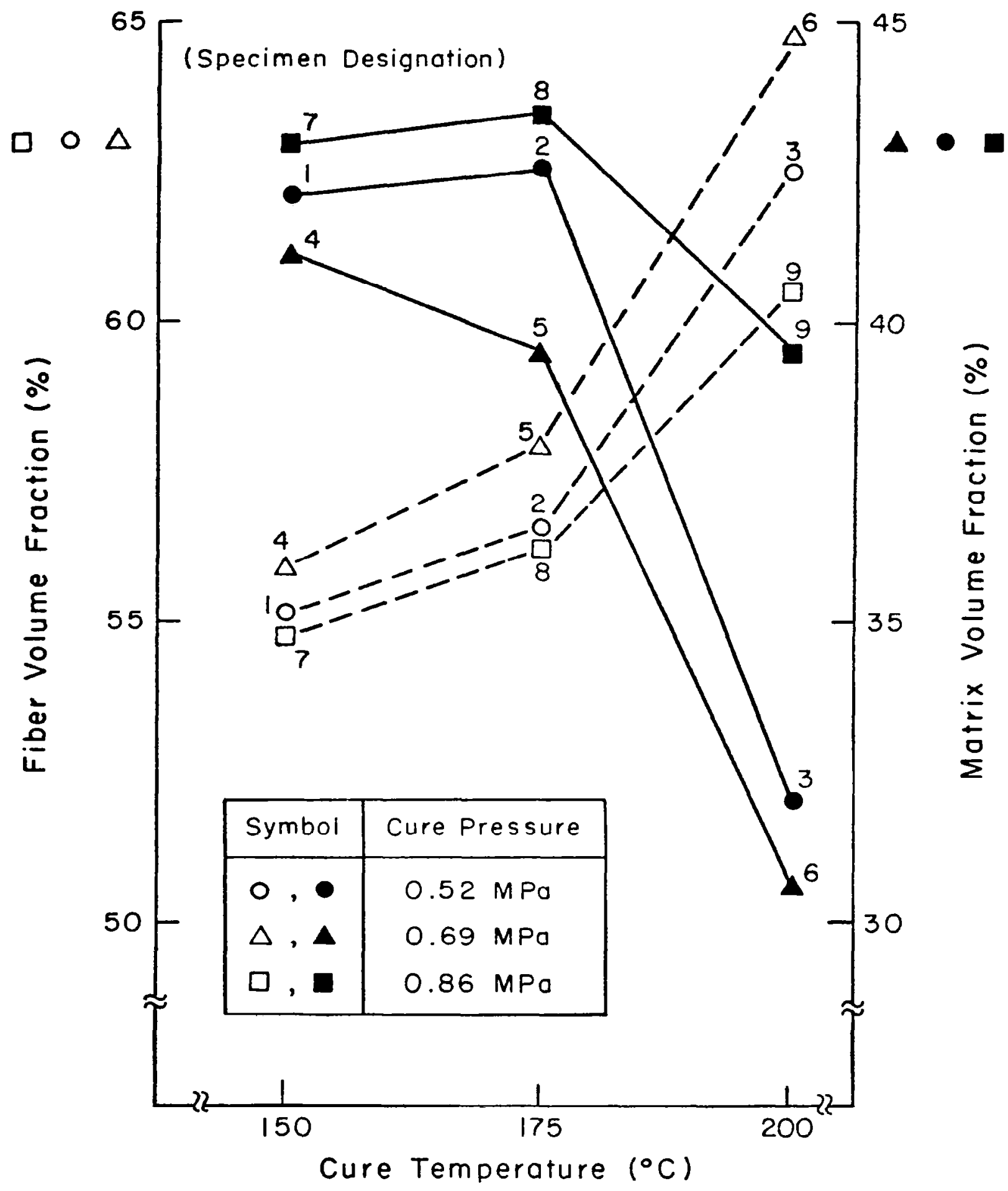

Fig. 3 Composite fiber and matrix volume fractions for variations in cure temperature and pressure.

$$
-17-
$$




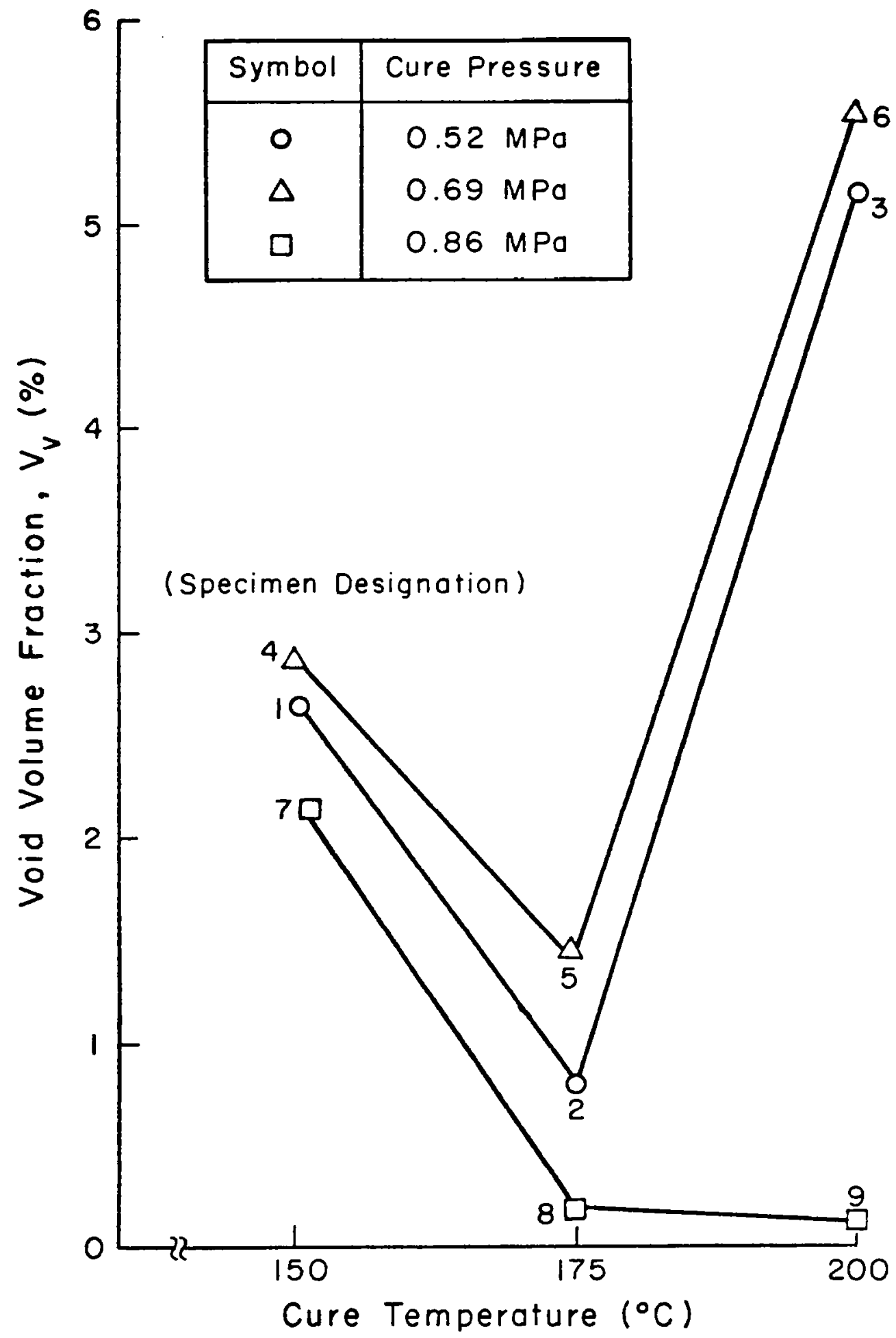

Fig. 4 Composite void volume fraction for variations in cure temperature. 


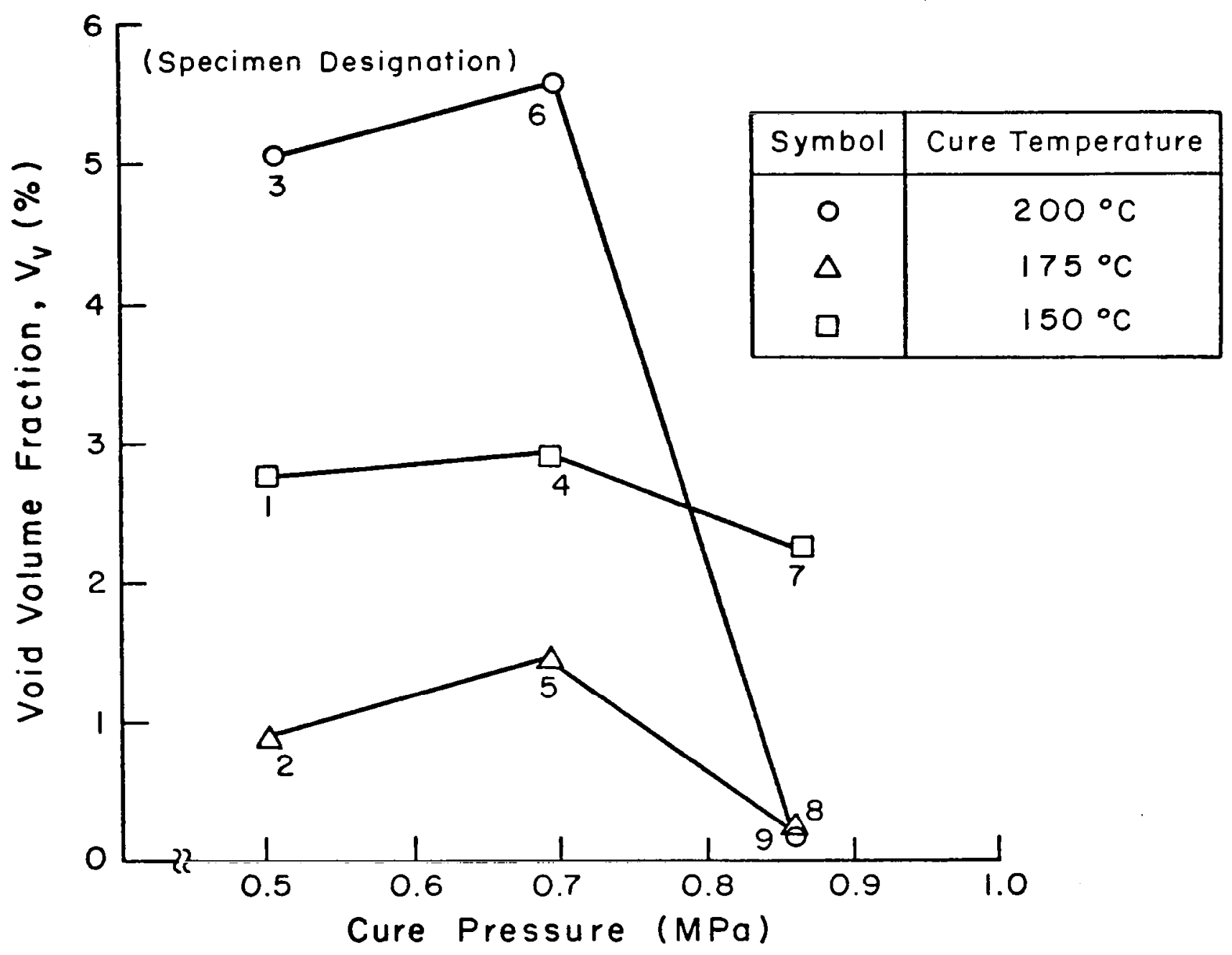

Fig. 5 Composite void volume fraction for variations in cure pressure. 


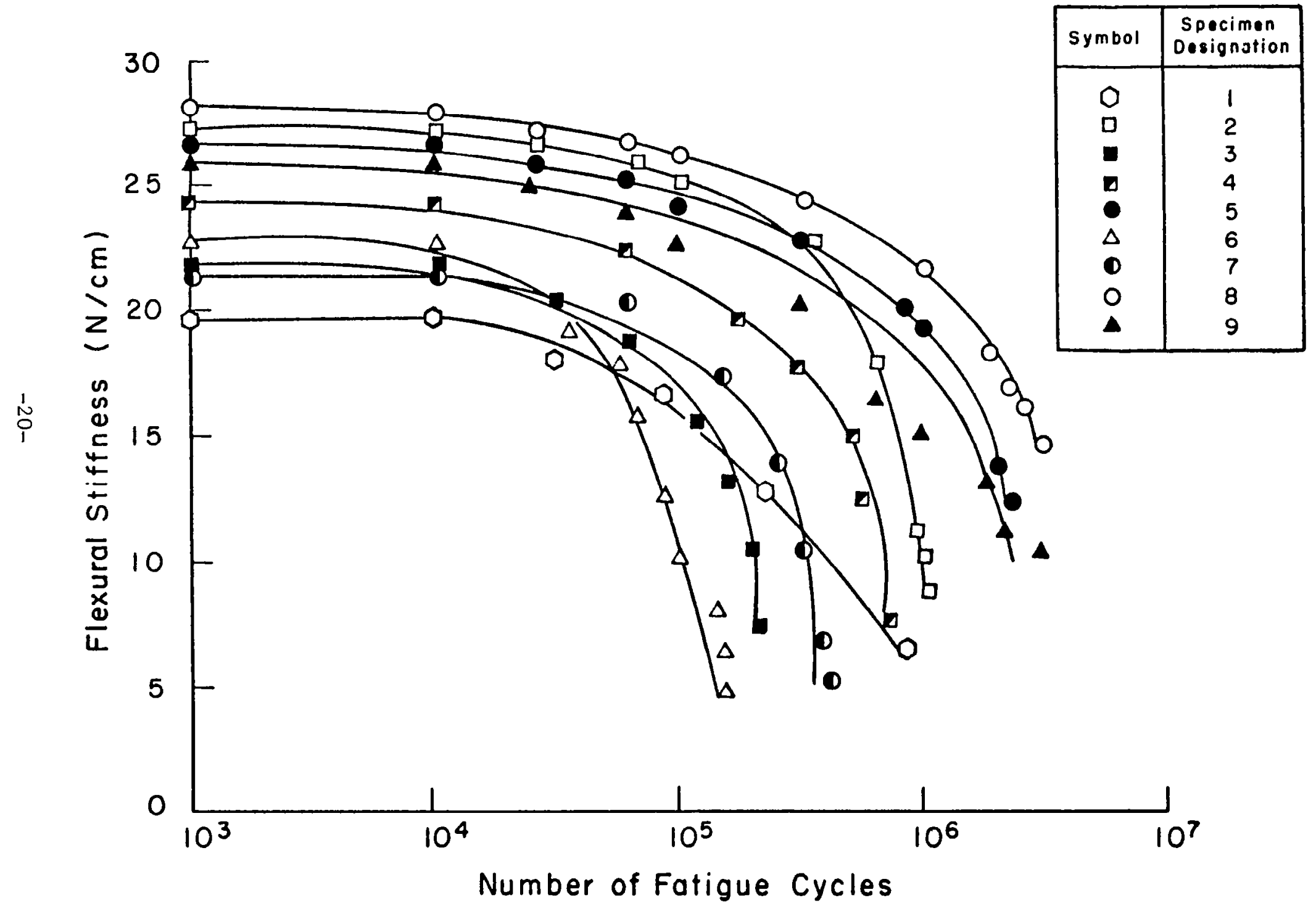

Fig. 6 Normalized flexural stiffness versus number of flexural fatigue cycles of AS/3501-6 $[0, \pm 45,0]_{\mathrm{S}}$ laminates fabricated by various cure pressures and temperatures. 


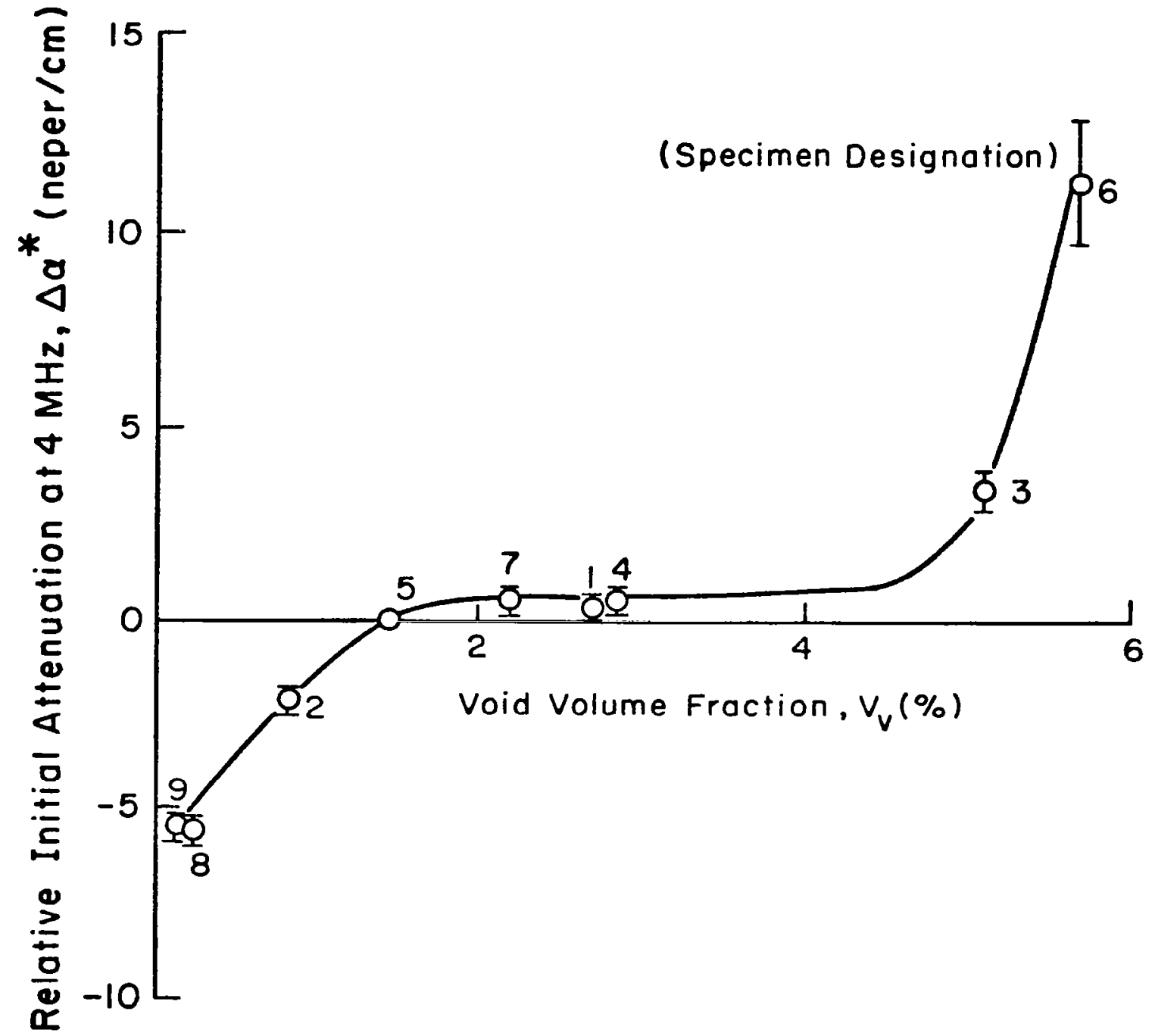

Fig. 7 Composite void volume fraction versus relative initial attenuation at $4.0 \mathrm{MHz}$ of as-fabricated specimens. 


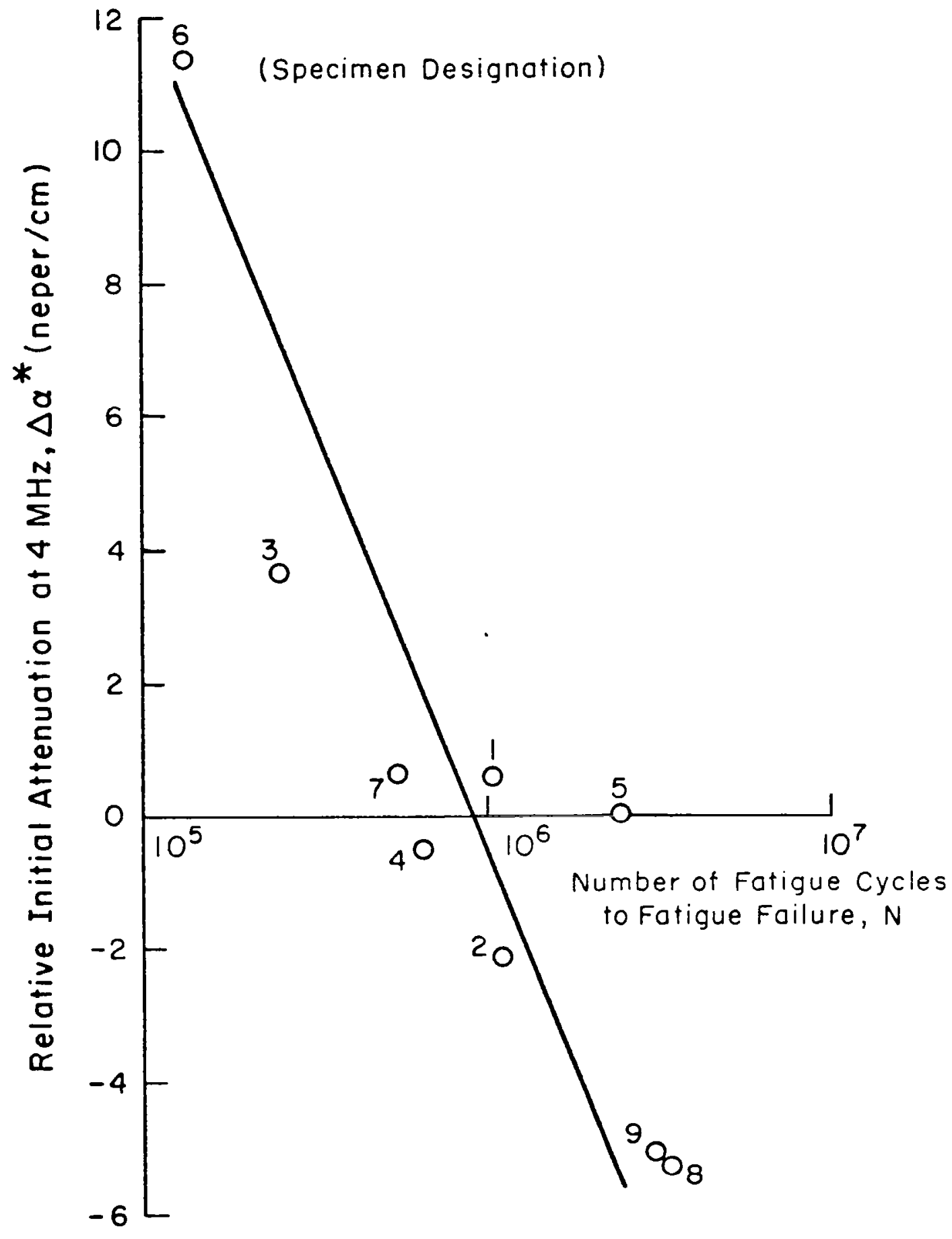

Fig. 8 Relative attenuation at $4.0 \mathrm{MHz}$ versus number of fatigue cycles to fatigue failure. 


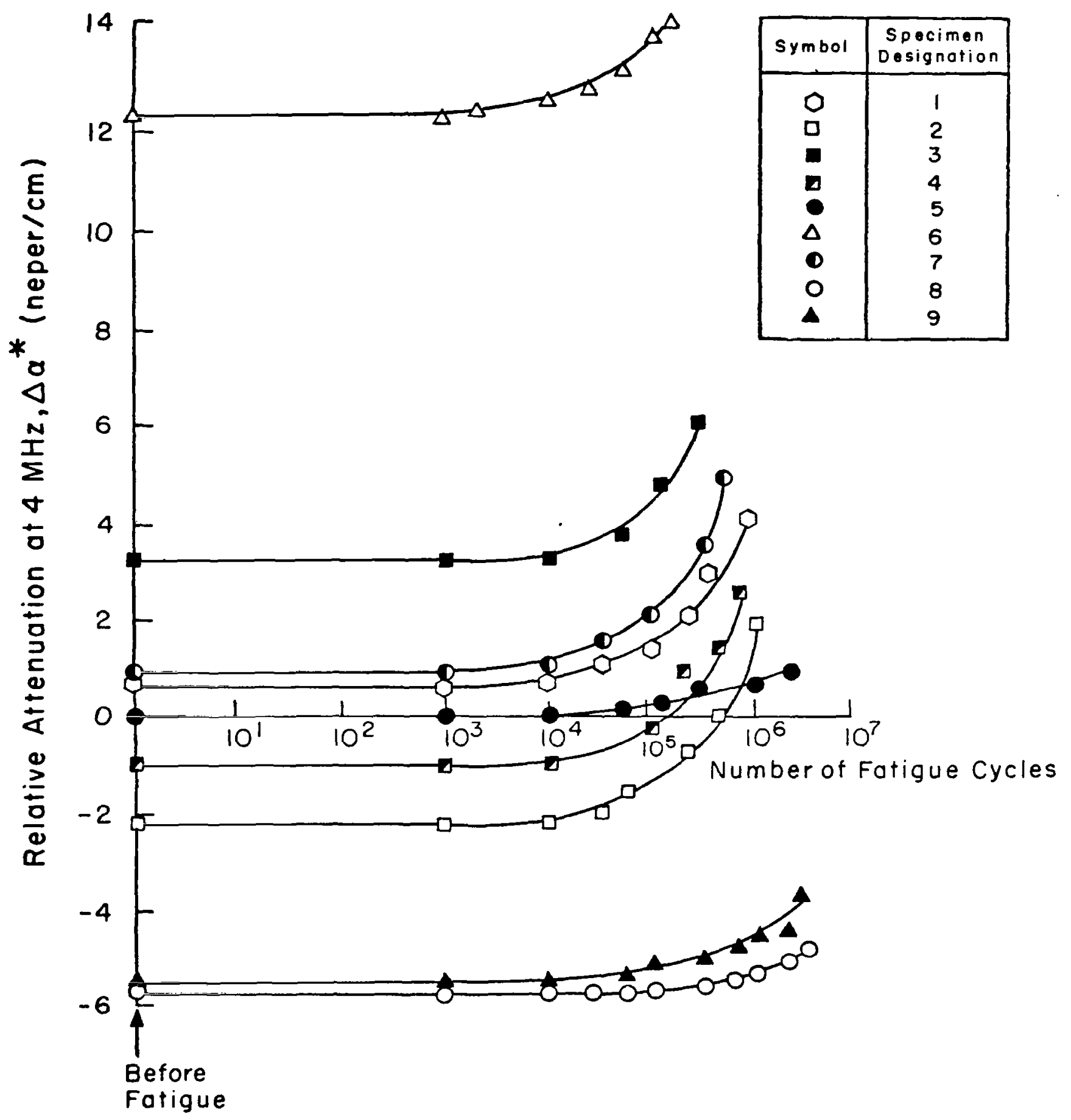

Fig. 9 Relative attenuation at $4.0 \mathrm{MHz}$ versus number of flexural fatigue cycles of AS/3501-6 [0, $\pm 45,0]_{S}$ laminates fabricated by various cure pressures and temperatures. 


\begin{tabular}{|c|c|c|c|c|}
\hline $\begin{array}{l}\text { 1. Report No. } \\
\text { NASA CR-3504 }\end{array}$ & \multicolumn{2}{|c|}{ 2. Government Accession No. } & \multicolumn{2}{|c|}{ 3. Recipient's Catalog No. } \\
\hline \multicolumn{3}{|c|}{$\begin{array}{l}\text { 4. Title and Subtitle } \\
\text { ULTRASONIC AND MECHANICAL CHARACTERIZATIONS OF FA- } \\
\text { TIGUE STATES OF GRAPHITE EPOXY COMPOSITE LAMINATES }\end{array}$} & \multicolumn{2}{|l|}{$\begin{array}{l}\text { 5. Report Date } \\
\text { January } 1982\end{array}$} \\
\hline \multicolumn{2}{|l|}{ 7. Author(s) } & James H. Williams, Jr., Hursit Yuce, and Samson S. Lee & \multicolumn{2}{|c|}{$\begin{array}{l}\text { 8. Performing Organization Report No. } \\
\text { None }\end{array}$} \\
\hline \multicolumn{3}{|c|}{$\begin{array}{l}\text { 9. Performing Organization Name and Address } \\
\text { Massachusetts Institute of Technology } \\
\text { Department of Mechanical Engineering } \\
\text { Cambridge, Massachusetts } 02139\end{array}$} & \multicolumn{2}{|c|}{$\begin{array}{l}\text { 11. Contract or Grant No. } \\
\text { NSG-3210 }\end{array}$} \\
\hline \multicolumn{3}{|c|}{$\begin{array}{l}\text { 12. Sponsoring Agency Name and Address } \\
\text { National Aeronautics and Space Administration } \\
\text { Washington, D.C. } 20546\end{array}$} & \multicolumn{2}{|c|}{$\begin{array}{l}\text { 14. Sponsoring Agency Code } \\
505-33-22\end{array}$} \\
\hline \multicolumn{5}{|c|}{$\begin{array}{l}\text { 15. Supplementary Notes } \\
\text { Final report. Project Manager, Alex Vary, Materials Division, NASA Lewis Rcsearch } \\
\text { Center, Cleveland, Ohio } 44135 \text {. }\end{array}$} \\
\hline \multicolumn{5}{|c|}{$\begin{array}{l}\text { 16. Abstract } \\
\text { Eight-ply }(0, \pm 45,0)_{\mathrm{S}} \text { laminates of Hercules AS/3501-6 graphite epoxy composite are fabri- } \\
\text { cated using various cure pressures ranging from } 0.52 \text { to } 0.86 \mathrm{MPa} \text { and cure temperatures } \\
\text { ranging from } 150^{\circ} \text { to } 200^{\circ} \mathrm{C} \text {. In general, the minimum composite void volume fraction is } \\
\text { obtained at a cure temperature of } 175^{\circ} \mathrm{C} \text { and a cure pressure of } 0.86 \mathrm{MPa} \text {, or at } 200^{\circ} \mathrm{C} \text { and } \\
0.86 \mathrm{MPa} \text {. The ultrasonic attenuation at } 4 \mathrm{MHz} \text { is found to correlate with the composite void } \\
\text { volume fraction. Composite specimens are tested in flexural fatigue. Beyond } 10,000 \text { fatigue } \\
\text { cycles, the ultrasonic attenuation at } 4 \mathrm{MHz} \text { is found to increase and the flexural stiffness is } \\
\text { found to decrease. Further, the ultrasonic attenuation at } 4 \mathrm{MHz} \text { of the as-fabricated compos- } \\
\text { ite can be correlated with the number of fatigue cycles to failure. }\end{array}$} \\
\hline $\begin{array}{l}\text { 17. Key Words (Suggested by Auth } \\
\text { Ultrasonics; Nondest } \\
\text { Flexural fatigue; Fat } \\
\text { Graphite/epoxy comp }\end{array}$ & $\begin{array}{l}\text { sts; Fatigue; } \\
\text { Composites; }\end{array}$ & $\begin{array}{l}\text { 18. Distrib } \\
\text { Unc } \\
\text { STA }\end{array}$ & unlimited & \\
\hline $\begin{array}{l}\text { 19. Security Classif. (of this report) } \\
\text { Unclassified }\end{array}$ & $\begin{array}{r}\text { 20. Security Classi } \\
\text { Un }\end{array}$ & $\begin{array}{l}f \text { this page) } \\
\text { ssified }\end{array}$ & $\begin{array}{l}\text { 21. No. of Pages } \\
25\end{array}$ & $\begin{array}{r}\text { 22. Price } \\
\mathrm{A02}\end{array}$ \\
\hline
\end{tabular}

*For sale by the National Technical Information Service, Springfield, Virginia 22161 